\title{
Identification of Blast Resistance in a Core Collection of Foxtail Millet Germplasm
}

Rajan Sharma, A. G. Girish, H. D. Upadhyaya, P. Humayun, T. K. Babu, V. P. Rao, and R. P. Thakur, International Crops Research Institute for the Semi-Arid Tropics, Hyderabad, Andhra Pradesh, India

\begin{abstract}
Sharma, R., Girish, A. G., Upadhyaya, H. D., Humayun, P., Babu, T. K., Rao, V. P., and Thakur, R. P. 2014. Identification of blast resistance in a core collection of foxtail millet germplasm. Plant Dis. 98:519-524.

Blast, also known as leaf spot, caused by Pyricularia grisea (teleomorph: Magnaporthe grisea), is a serious disease affecting both forage and grain production in foxtail millet in India. For the identification of new and diverse sources of blast resistance, a foxtail millet core collection comprising 155 accessions was evaluated against the Patancheru isolate (Fx 57) of M. grisea. In a field screen during 2009 and 2010, 21 accessions were identified with neck and head blast resistance against Fx 57. In a greenhouse screen, 11 of the 155 accessions exhibited seedling leaf blast resistance to the same isolate. Further evaluation of the selected 28 accessions (found resistant to neck and head blast under field conditions during 2009 and 2010 or leaf blast in the greenhouse

screen) against four M. grisea isolates (Fx 57, Fx 58, Fx 60, and Fx 62 from Patancheru, Nandyal, Vizianagaram, and Mandya, respectively) led to the identification of 16 accessions with leaf, sheath, neck, and head blast resistance to at least one isolate. Two accessions (ISe 1181 and ISe 1547) were free from head blast infection and showed resistance to leaf (score $\leq 3.0$ on a 1 -to- 9 scale), neck, and sheath blast (score $\leq 2.0$ on a 1-to-5 scale) against all four isolates. In addition, ISe 1067 and ISe 1575 also exhibited high levels of blast resistance. Blastresistant accessions with superior agronomic and nutritional quality traits can be evaluated in multilocation yield trials before releasing them for cultivation to farmers.
\end{abstract}

Foxtail millet (Setaria italica (L.) Beauv.) is one of the 10 smallgrained cereals (small millets) grown as a food crop in Asia and for animal feed in the United States and Europe (19). China, India, and Japan are the chief foxtail-millet-growing countries, and the millet is believed to have been first domesticated in central China (4). Foxtail millet comprises two subspecies, $S$. italica subsp. italica and subsp. viridis. S. italica subsp. viridis is considered as the progenitor of the cultivated form. Based on the comparative morphology of the foxtail millet accessions, Prasada Rao et al. $(14,15)$ suggested three races of foxtail millet-moharia, common in Europe, southeast Russia, Afghanistan, and Pakistan; maxima, common in eastern China, Georgia (Eurasia), Japan, Korea, Nepal, and northern India (it has also been introduced in the United States); and race indica in the remaining parts of India and Sri Lanka. Another report mentions four races (maxima, moharia, indica, and nana), each related to a specific geographic region-maxima from East Asia, moharia from Europe, indica from South Asia, and nana from Afghanistan and Lebanon (11).

In India, foxtail millet is grown on about 1 million ha, mainly in northern Karnataka, parts of costal Andhra Pradesh, Uttarakhand, Tamil Nadu, and some parts of the northeastern states. The grain is used both for food and feed. A seed oil content of $5.45 \%$, with a range between 4.0 and $7.3 \%$, has been reported in the foxtail millet germplasm (18). The grain is also a rich source of protein, minerals (calcium, iron, potassium, magnesium, and zinc) and vitamins (16). It is widely used not only as an energy source for pregnant and lactating women but also for sick people and children, and especially for diabetics (20). It has been suggested that foxtail millet protein be used as a food component to fight type 2 diabetes and cardiovascular diseases (6). In general, foxtail millet is valued as a crop of short growth duration, which is fairly resistant to insect pests and diseases, with grain that makes a nutritious and healthy

Corresponding author: R. Sharma, E-mail: r.sharma@ cgiar.org

Accepted for publication 14 October 2013.

http://dx.doi.org/10.1094/PDIS-06-13-0593-RE

(C) 2014 The American Phytopathological Society food. However, blast disease is the only yield-limiting biotic constraint to this crop, especially in northern China and India (12).

Blast caused by the fungus Pyricularia grisea Sacc. (teleomorph: Magnaporthe grisea (T.T. Herbert) M.E. Barr) affects both forage and grain production of foxtail millet. Symptoms of the disease appear as circular spots with straw-colored centers on leaf blades. The spots are small and scattered, 2 to $5 \mathrm{~mm}$ in diameter, and surrounded by a dark brown margin. When the disease appears in severe form during humid weather conditions, especially with a dense plant stand, the leaves wither and dry. Plants are infected at all growth stages (9); lower leaves are the most severely affected. Node, neck, and stem tissues are also infected in addition to leaf sheaths. The blast pathogen infects several cereal crops, including rice, wheat, pearl millet, finger millet, and foxtail millet, and several grasses $(12,13,21,26)$. The pathogen is variable but highly specialized in its host range. Thus, $M$. grisea strains from rice or any other hosts do not infect foxtail millet and vice versa.

The disease can be best managed through host plant resistance; therefore, extensive screening for blast resistance among local cultivars of foxtail millet has been conducted in India and China $(5,7,24)$. However, differential reactions of cultivars have been observed among Chinese cultivars, demonstrating the existence of pathogenic races among $M$. grisea populations adapted to foxtail millet (33). Therefore, it is important to evaluate foxtail millet germplasm of diverse geographic origins to identify new sources of blast resistance for utilization in breeding programs. In this context, plant genetic resources conserved in gene banks can be tapped for the identification of resistance sources (29). The gene bank at the International Crops Research Institute for the Semi-Arid Tropics (ICRISAT), Patancheru, India has assembled 1,535 foxtail millet accessions from 26 countries. However, the large number of accessions in the germplasm collections often hinders their evaluation and utilization for specific breeding purposes. To overcome these problems, Frankel and Brown (8) proposed the establishment of a core collection (10\% of the total) that could be selected from the existing collection of crop species resources in a gene bank. Core collections based on phenotypic data have been reported in several crops $(3,27,28,32)$. Using passport information and data on 23 morphological descriptors, Upadhyaya et al. (29) developed a core collection consisting of 155 foxtail millet accessions. This 
core collection comprises accessions of all the races and subraces of foxtail millet of diverse geographical origins. The present study was planned to evaluate all accessions in the foxtail millet core collection against $M$. grisea to identify new and diverse sources of blast resistance.

\section{Materials and Methods}

Seed source. Seed of the 155 germplasm accessions of the foxtail millet core collection comprising three races-indica $(n=$ $102)$, maxima ( $n=24)$, and moharia $(n=29)$-was obtained from the ICRISAT gene bank at Patancheru, India.

Pathogen isolates. Cultures of M. grisea were established from diseased samples collected from the foxtail millet fields in the 2008 rainy season from Patancheru (Fx 57), Nandyal (Fx 58), Vizianagaram (Fx 60), and Mandya (Fx 62), India. Isolations were made from diseased samples on oatmeal agar (OA) medium and the pathogen was purified through single-spore isolation. Mass multiplication of fungal spores for inoculation was achieved by growing the fungus on OA medium in petri plates ( 9 discs/plate) at $25 \pm 1^{\circ} \mathrm{C}$ for 10 days. The plates were flooded with $20 \mathrm{ml}$ of sterile distilled water and the fungal growth containing mycelium and conidia was gently removed by scraping with a plastic inoculation loop. The suspension was transferred to a $100-\mathrm{ml}$ conical flask, stirred to facilitate the release of conidia into water, and filtered through a muslin cloth (1). The conidial concentration was adjusted to $1 \times 10^{5}$ spores $\mathrm{ml}^{-1}$ and 3 to 4 drops of Tween 20 were added to the suspension just before using it for inoculation.

Field evaluation of foxtail millet core collection for blast resistance. The foxtail millet core collection, comprising 155 accessions along with four checks (ISe 375, -376, -1468, and -1541) was evaluated at Patancheru $\left(18^{\circ} 31^{\prime} \mathrm{N}, 78^{\circ} 16^{\prime} \mathrm{E}, 545 \mathrm{~m}\right.$ above sea level, and $600 \mathrm{~km}$ from the sea), Andhra Pradesh, India in a randomized complete block design with two replicates, one row of $2 \mathrm{~m}$ long/replicate, for neck and head blast resistance during the 2009 and 2010 rainy seasons following artificial inoculation with the Patancheru isolate (Fx 57) of M. grisea. The susceptible line (ISe 1118) was planted at every fifth row to increase disease pressure. Plants were thinned to 20 plants/row at 15 days after emergence and spray inoculated until runoff at tillering with an aqueous conidial suspension of $M$. grisea isolate Fx 57 at $1 \times 10^{5}$ spores $\mathrm{ml}^{-1}$. This was done during the evening hours using a knapsack power sprayer. High humidity and leaf wetness was provided by perfoirrigation twice a day on rain-free days, 30 min each during morning and evening hours to facilitate disease development. Blast incidence (neck and head) was recorded as percentage of infected plants in a row at the dough stage. Based on blast incidence, these accessions were categorized into resistant ( $\leq 10 \%$ incidence), moderately resistant (11 to $30 \%$ ), susceptible (31 to $50 \%$ ), and highly susceptible ( $>50 \%$ incidence).

Greenhouse evaluation for leaf blast resistance. For leaf blast resistance, core collection accessions were evaluated at the seedling stage in a greenhouse. The experiment was conducted in a completely randomized design (CRD) with two replicates, 1 pot/replicate, and 10 plants/pot. The 15-day-old potted seedlings were spray inoculated until runoff with an aqueous conidial suspension of Fx 57 at $1 \times 10^{5}$ spores $\mathrm{ml}^{-1}$, covered with polyethylene bags, and incubated at $25^{\circ} \mathrm{C}$ for $24 \mathrm{~h}$. Bags were then removed and the inoculated seedlings were exposed to $>90 \%$ relative humidity (RH) under misting for 7 days in a greenhouse. Percentage of diseased leaf area was visually assessed 10 days after inoculation (DAI) and leaf blast severity was recorded using a progressive 1to-9 scale, where $1=$ no lesions to small brown specks of pinhead size and $9=>75 \%$ leaf area covered with lesions or all the leaves dead (1).

Identification of resistance to different isolates of $M$. grisea. Twenty-five accessions (found resistant to neck and head blast under field conditions during both 2009 and 2010 or leaf blast in the greenhouse screen) were further screened for leaf, sheath, neck, and head blast resistance against four $M$. grisea isolates (Fx 57, Fx 58, Fx 60, and Fx 62) along with germplasm checks (ISe 376 and
-1541) and a susceptible check (ISe 1118). In addition, ISe 1204, which was found resistant in a 2010 field screen but failed to germinate in 2009, was also included in the screening. The experiment was conducted in a CRD with two replicates, 1 pot/replicate, 10 plants/pot for leaf blast, and 5 plants/pot for sheath, neck, and head blast screening. For leaf blast reaction, 15-day-old seedlings were screened as described above. For sheath, neck, and head blast reaction, plants were inoculated at anthesis, covered with polyethylene bags, and incubated at $25^{\circ} \mathrm{C}$ for $24 \mathrm{~h}$ to prevent cross contamination. Bags were then removed and the inoculated plants were exposed to $>90 \% \mathrm{RH}$ under misting for 7 days in a greenhouse. Lesion size was measured on the sheaths and necks of infected plants and a 1 -to-5 progressive rating scale $(1=$ no lesions to pinhead size and $2=0.1$ to $1.0,3=1.1$ to $2.0,4=2.1$ to 4.0 , and $5=>4.0 \mathrm{~cm}$ of lesions on the neck or sheath region) was used to record the neck and sheath blast severity at dough stage (1). Head blast was recorded as a percentage of infected panicles at maturity.

Evaluation for agronomic and nutritional traits. The foxtail millet core collection was evaluated for agronomic traits (days to $50 \%$ flowering, plant height, and basal tiller number) and nutritional traits (protein and minerals contents during rainy season 2008) along with four controls (ISe 375, ISe 376, ISe 1468, and ISe 1541), as described previously (28). The experiment was conducted in an $\alpha$-lattice design with three replicates, where each plot consisted of one row of $4 \mathrm{~m}$. Data on days to $50 \%$ flowering, plant height, and basal tillers were recorded using the foxtail millet descriptors (10). Data on plant height and basal tillers were recorded from five randomly selected plants. A random well-cleaned grain sample from each plot was used to record observations on grain protein, calcium $(\mathrm{Ca})$, iron $(\mathrm{Fe})$, and zinc $(\mathrm{Zn})$ concentrations in the core collection accessions. Grain samples were powdered and digested using the tri-acid mixture, and $\mathrm{Ca}, \mathrm{Fe}$, and $\mathrm{Zn}$ in the digests were determined by atomic absorption spectrometer (17), while protein was determined in the digests using an Autoanalyzer (22).

Statistical analysis. The replicate-wise values of disease scores were used for statistical analysis of each environment (where "environment" is field screen 2009-10 or greenhouse screen) using the residual maximum likelihood (REML) method and considering genotypes as random effects. Variance components due to genotypes $\left(\sigma_{\mathrm{g}}^{2}\right)$ and error $\left(\sigma_{\mathrm{er}}^{2}\right)$ and their standard errors were determined. Environment-wise best linear unbiased predictors for the core accessions were calculated. The significance of variance components were tested using respective standard errors.

For the pooled analysis, homogeneity of variance was tested using Bartlett's test (2). Environment was considered a fixed effect. The variances due to genotypes $\left(\sigma_{\mathrm{g}}^{2}\right)$ and genotype-environment interaction $\left(\sigma_{\text {ge }}^{2}\right)$ and their standard errors were determined. The significance of environment was assessed using the Wald statistic (31) that asymptotically follows a $\chi^{2}$ distribution.

The associations between pairs of variables such as leaf, neck, sheath, and head blast were determined in terms of Pearson's correlation coefficients using the correlation procedure in SAS (SAS/STAT 9.2 User's Guide; SAS Institute Inc.).

\section{Results}

Blast resistance in the field screen. REML analysis indicated significant genotypic variance in both years separately and genotypic and genotype-environment variances in the pooled analysis (Table 1). The Wald statistic indicated significant differences between seasons. Therefore, data of two seasons were not averaged to categorize the accessions into resistant, moderately resistant, susceptible, and highly susceptible. One accession, ISe 1204, failed to germinate in the 2009 field screen. Of the remaining 154 accessions, 34 were found resistant, 96 moderately resistant, 16 susceptible, and 8 highly susceptible during 2009; whereas, in 2010, numbers of accessions in the resistant, moderately resistant, susceptible, and highly susceptible categories were 46, 65, 15, and 29, respectively (Fig. 1). However, 20 accessions (ISe 375, -748, -751, $-769,-771,-785,-846,-1059,-1067,-1137,-1286,-1320,-1335$, 
$-1387,-1419,-1547,-1563,-1593,-1685$, and -1704) were found resistant in both years. Although ISe 1204 failed to germinate in 2009, it was found resistant in the 2010 field screen. In addition, two germplasm checks, ISe 376 and ISe 1541, were also found resistant in both years. Thus, these 23 accessions were selected for further screening against four isolates (Fx 57, Fx 58, Fx 60, and Fx 62) of M. grisea.

Leaf blast resistance in the greenhouse screen. Greenhouse screening of foxtail millet core accessions for leaf blast reaction at seedling stage identified 11 accessions resistant $(\leq 3.0$ score on a 1 to-9 scale) to leaf blast. Two accessions, ISe 828 and ISe 1209, did not germinate and, thus, could not be evaluated for leaf blast resistance. In all, 23 accessions were moderately resistant (3.1 to 5.0 score), 18 were susceptible (5.1 to 7.0 score), and the remaining 101 were highly susceptible ( $>7.0$ score) to Fx 57 (Fig. 1). Of the 11 leaf blast-resistant accessions, 6 (ISe 375, -1059, -1067, -1547, -1563, and -1685) were also found resistant in the field screens of both 2009 and 2010. The resistant accessions were selected for further screening against four isolates Fx 57, Fx 58, Fx 60, and Fx 62 of M. grisea.

Resistance to different isolates of $M$. grisea. REML analysis of the selected accessions screened in the greenhouse for leaf, sheath, neck, and head blast resistance against four isolates indicated significant variation due to genotypes, isolates, and their interactions (Table 2). Significant mean square variance due to isolates indicated pathogenic variation among the isolates used in this study.
This variation was further confirmed by the differential leaf blast reaction of 14 accessions against the four isolates. Susceptible check ISe 1118 recorded 6 to 9 leaf blast scores on a 1-to-9 scale, 3.6 to 4.9 sheath blast and 3.5 to 4.7 neck blast scores on a 1-to-5 scale, and 63 to $100 \%$ head blast incidence against test isolates, indicating adequate disease pressure and a reliable disease screen. ISe 1286 was also found highly susceptible to leaf, sheath, neck, and head blast against all four isolates.

Among the 28 accessions (including germplasm checks ISe 376 and -1541) screened against four $M$. grisea isolates, two (ISe 1181 and ISe 1547) were found to have leaf blast (seedling stage) resistance against all four isolates (Table 3). Six accessions had leaf blast resistance against three, five against two, and three against only one isolate. The remaining accessions recorded $\geq 5.0$ score to M. grisea isolates.

Most of the accessions, except ISe 1286, selected from the core collection exhibited adult plant resistance $(\leq 2.0$ score for sheath or neck blast and $\leq 10 \%$ head blast incidence) to at least one isolate of $M$. grisea. Sheath, neck, and head blast resistance was observed in 15 accessions against all four isolates. Two accessions, ISe 1181 and ISe 1547, were free from head blast and resistant to leaf, neck, and sheath blast against all four isolates. In addition, ISe 1067 and ISe 1575 exhibited seedling leaf blast resistance to three isolates (Fx 57, Fx 58, and Fx 62) and sheath, neck, and head blast resistance to all four isolates (Table 3).

Table 1. Variance components due to genotypes $\left(\sigma_{\mathrm{g}}^{2}\right)$, genotype-environment $\left(\sigma_{\mathrm{ge}}^{2}\right)$, and their standard errors (s.e.) for blast reaction in the foxtail millet core collection

\begin{tabular}{|c|c|c|c|c|c|c|c|}
\hline Disease screen & Season & $\sigma_{g}^{2}$ & s.e. & $\sigma_{\text {ge }}^{2}$ & s.e. & Wald statistics (season) & $F$ prob \\
\hline \multirow[t]{3}{*}{ Field } & 2009 & 159.0 & 27.1 & $\ldots$ & $\ldots$ & $\ldots$ & $\ldots$ \\
\hline & 2010 & 517.61 & 64.10 & - & $\ldots$ & $\ldots$ & 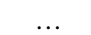 \\
\hline & Pooled & 122.9 & 33.3 & 216.5 & 31.6 & 9.66 & 0.009 \\
\hline Greenhouse & $\ldots$ & 4.8680 & 0.5610 & $\ldots$ & $\ldots$ & $\ldots$ & $\ldots$ \\
\hline
\end{tabular}

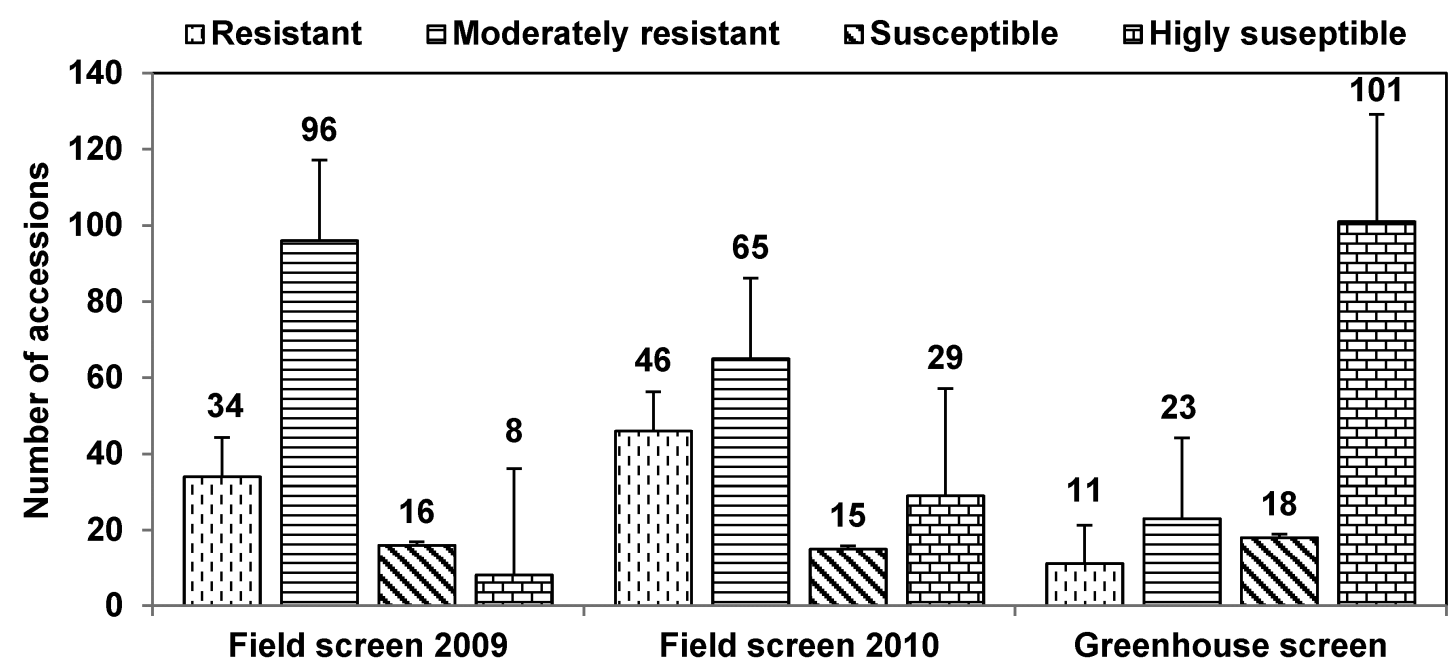

Fig. 1. Summary of blast reaction of 155 accessions ( 2 accessions failed to germinate in the greenhouse screen and 1 in the 2009 field screen) of foxtail millet core collection under field (neck and head blast) and greenhouse (seedling leaf blast) conditions. Resistant $=\leq 10 \%$ blast incidence in the field and $\leq 3.0$ score on a 1 -to-9 scale in the greenhouse; moderately resistant $=11$ to $30 \%$ blast incidence in the field and 3.1 to 5.0 score in the greenhouse; susceptible $=31$ to $50 \%$ blast incidence in the field and 5.1 to 7.0 score in the greenhouse; highly susceptible $=>50 \%$ blast incidence in the field and $>7.0$ score in the greenhouse. Vertical bars indicate standard error.

Table 2. Variance components due to genotypes, isolates, and their interactions for the leaf, sheath, neck, and head blast in the selected foxtail millet accessions evaluated under greenhouse conditions during December 2011 to April 2012a

\begin{tabular}{|c|c|c|c|c|c|}
\hline \multirow[b]{2}{*}{ Source of variation } & \multirow[b]{2}{*}{ Degree of freedom } & \multicolumn{4}{|c|}{ Mean square } \\
\hline & & Leaf blast & Sheath blast & Neck blast & Head blast \\
\hline Isolate & 3 & $38.54 * * *$ & $5.03 * * *$ & $6.49 * * *$ & $8.38 * * *$ \\
\hline Genotype & 28 & $325.86 * * *$ & $45.71 * * *$ & $94.23 * * *$ & $76.06 * * *$ \\
\hline Isolate-genotype & 84 & $37.9 * * *$ & $3.77 * * *$ & $5.04 * * *$ & $8.13 * * *$ \\
\hline
\end{tabular}

a Asterisks (***) indicate significant at $P \leq 0.001$. 
Agronomic performance and nutritional quality of blast-resistant accessions. In all, 15 of the 28 selected accessions were early flowering compared with the mean (54.75 days) days to $50 \%$ flowering of the 155 accessions of the core collection (Table 4). Among these, six (ISe 1201, -1258, -1286, -1320, -1335, and -1563 ) accessions took $\leq 40$ days to $50 \%$ flowering. Blast-resistant accessions ISe 1201 and ISe 1419 were the shortest $(29.7 \mathrm{~cm})$ and tallest $(155.6 \mathrm{~cm})$, respectively, among the 155 accessions. The average plant height of the 28 selected accessions $(79.2 \mathrm{~cm})$ was less than the average height $(83.79 \mathrm{~cm})$ of the core collection. Significant variation for basal tiller number was also observed in the selected accessions. Ten accessions had more basal tillers than the average $(n=2.21)$ of the core collection. However, only five accessions recorded higher grain yield than the average $\left(1,046.32 \mathrm{~kg} \mathrm{ha}^{-1}\right)$ of the core collection. ISe 1541 recorded the maximum grain yield $\left(1,852.5 \mathrm{~kg} \mathrm{ha}^{-1}\right)$ among the 28 selected accessions.

Significant variation for nutritional quality traits $(\mathrm{Ca}, \mathrm{Fe}, \mathrm{Zn}$, and percent protein) was also observed in the blast-resistant accessions. Of the 28 accessions, 16 had more $\mathrm{Ca}$ than the average $(145.82 \mathrm{ppm})$ for the entire core collection. Similarly, 15, 11, and 13 accessions had more $\mathrm{Fe}, \mathrm{Zn}$, and protein, respectively, compared with the mean of the core collection.

\section{Discussion}

Twenty-one accessions resistant to neck and head blast were selected from the field evaluation of foxtail millet core collection under artificial inoculation. In total, 11 of the 155 core accessions also had seedling leaf blast resistance in the greenhouse screening against the Patancheru isolate (Fx 57) of M. grisea. Further evaluation of the selected 28 accessions including two germplasm checks (with neck and head blast resistance in the field or leaf blast resistance in the greenhouse) against four isolates of $M$. grisea led to the identification of 16 accessions with resistance to leaf, sheath, neck, and head blast to at least one isolate. Though 12 of the 28 selected accessions exhibited seedling leaf blast susceptibility to all four $M$. grisea isolates, most of these accessions had adult plant resistance to sheath, neck, and head blast. A weak correlation ( $r=$ 0.2 to 0.5 ) was observed between seedling (leaf blast) and adult plant (sheath, neck, and head blast) reaction, whereas correlation between sheath, neck, and head blast screening was high $(r=0.83$ to $0.92, P<0.001)$. Contrasting responses between the vegetative stage and the reproductive stage resistance often occur. Differential expression for resistance to leaf, neck, or finger blast infection in finger millet has been reported (1). Similarly, some genes responsible for seedling leaf blast resistance in rice were not found effective at the reproductive stage (23). Thus, there could be different genes responsible for seedling and adult plant resistance to $M$. grisea in foxtail millet.

Many pathogenic races have been identified in $M$. grisea infecting rice, and this variability has been cited as the principal cause for the frequent breakdown of resistance in rice varieties (25). Although pathogenic variations in the M. grisea populations adapted to rice, wheat, foxtail millet, finger millet, pearl millet, and several weed hosts have been reported $(12,13,21,26)$, there is no infor-

Table 3. Leaf, neck, sheath, and head blast scores of the selected foxtail millet accessions evaluated against four Magnaporthe grisea isolates under greenhouse conditions during December 2011 to April $2012^{\text {a }}$

\begin{tabular}{|c|c|c|c|c|c|c|c|c|c|c|c|c|c|c|c|c|}
\hline \multirow[b]{2}{*}{$\mathbf{I S e}^{\mathbf{b}}$} & \multicolumn{4}{|c|}{ Leaf blast (1-9 scale) } & \multicolumn{4}{|c|}{ Sheath blast (1-5 scale) } & \multicolumn{4}{|c|}{ Neck blast (1-5 scale) } & \multicolumn{4}{|c|}{ Head blast (\%) } \\
\hline & Fx 57 & Fx 58 & Fx 60 & Fx 62 & Fx 57 & Fx 58 & Fx 60 & Fx 62 & Fx 57 & Fx 58 & Fx 60 & Fx 62 & Fx 57 & Fx 58 & Fx 60 & Fx 62 \\
\hline 375 & 3.0 & 3.0 & 4.0 & 2.0 & 1.0 & 1.0 & 1.0 & 1.0 & 1.0 & 1.0 & 1.0 & 1.0 & 0.0 & 40.0 & 0.0 & 0.0 \\
\hline 376 & 2.0 & 3.0 & 4.0 & 3.0 & 1.0 & 1.0 & 1.0 & 1.0 & 1.0 & 1.0 & 1.0 & 1.0 & 0.0 & 80.0 & 0.0 & 0.0 \\
\hline 748 & 6.0 & 5.0 & 7.0 & 6.0 & 1.0 & 1.5 & 1.2 & 1.0 & 1.1 & 1.0 & 1.1 & 1.0 & 0.0 & 0.0 & 0.0 & 0.0 \\
\hline 751 & 7.0 & 5.0 & 6.0 & 5.5 & 1.3 & 1.0 & 1.2 & 1.0 & 1.0 & 1.0 & 1.0 & 1.0 & 0.0 & 0.0 & 0.0 & 0.0 \\
\hline 769 & 5.0 & 5.0 & 6.0 & 4.0 & 1.0 & 1.0 & 1.0 & 1.0 & 1.0 & 1.0 & 1.0 & 1.0 & 0.0 & 0.0 & 0.0 & 0.0 \\
\hline 771 & 9.0 & 8.0 & 8.0 & 8.0 & 1.0 & 2.7 & 1.8 & 1.8 & 1.0 & 1.4 & 1.0 & 1.0 & 0.0 & 0.0 & 0.0 & 0.0 \\
\hline 785 & 9.0 & 8.0 & 8.0 & 8.0 & 3.9 & 3.7 & 1.4 & 1.7 & 2.1 & 1.0 & 1.0 & 1.0 & 0.0 & 10.0 & 0.0 & 20.0 \\
\hline 846 & 8.5 & 6.0 & 7.0 & 6.0 & 1.0 & 2.2 & 1.0 & 1.3 & 1.0 & 2.8 & 1.0 & 1.0 & 0.0 & 50.0 & 0.0 & 0.0 \\
\hline 1059 & 3.0 & 5.0 & 5.0 & 3.0 & 1.0 & 1.0 & 1.0 & 1.0 & 1.0 & 1.0 & 1.0 & 1.0 & 0.0 & 0.0 & 0.0 & 0.0 \\
\hline 1067 & 2.0 & 3.0 & 4.0 & 2.0 & 1.0 & 1.0 & 1.0 & 1.0 & 1.0 & 1.1 & 1.2 & 1.0 & 0.0 & 0.0 & 0.0 & 0.0 \\
\hline 1137 & 8.5 & 8.0 & 7.0 & 3.0 & 2.0 & 2.2 & 1.4 & 2.8 & 1.0 & 1.1 & 1.0 & 1.4 & 20.0 & 0.0 & 0.0 & 60.0 \\
\hline 1181 & 1.0 & 2.0 & 3.0 & 3.0 & 1.0 & 1.0 & 1.0 & 1.0 & 2.0 & 1.0 & 1.0 & 1.0 & 0.0 & 0.0 & 0.0 & 0.0 \\
\hline 1187 & 3.0 & 3.0 & 3.0 & 4.0 & 1.0 & 1.0 & 1.0 & 1.5 & 2.0 & 1.0 & 1.0 & 1.0 & 0.0 & 0.0 & 0.0 & 50.0 \\
\hline 1201 & 2.0 & 4.0 & 6.0 & 3.0 & 1.0 & 1.0 & 1.0 & 1.0 & 2.0 & 1.0 & 1.0 & 1.0 & 0.0 & 0.0 & 0.0 & 0.0 \\
\hline 1204 & 6.0 & 4.0 & 3.0 & 3.0 & 1.0 & 1.0 & 1.0 & 1.0 & 1.0 & 1.0 & 1.0 & 1.0 & 0.0 & 0.0 & 0.0 & 0.0 \\
\hline 1258 & 2.0 & 8.0 & 7.0 & 7.0 & 1.0 & 1.0 & 1.0 & 1.0 & 2.0 & 1.0 & 1.0 & 1.0 & 0.0 & 0.0 & 25.0 & 0.0 \\
\hline 1286 & 6.0 & 7.0 & 6.0 & 5.0 & 4.5 & 4.4 & 4.2 & 3.0 & 4.4 & 3.7 & 3.7 & 2.0 & 100.0 & 83.3 & 80.0 & 40.0 \\
\hline 1320 & 5.5 & 5.0 & 6.0 & 6.0 & 1.5 & 2.0 & 1.4 & 1.0 & 1.0 & 1.6 & 1.0 & 1.0 & 0.0 & 0.0 & 0.0 & 0.0 \\
\hline 1335 & 9.0 & 7.0 & 6.0 & 5.0 & 2.4 & 2.8 & 3.3 & 1.9 & 1.0 & 1.1 & 1.2 & 1.0 & 12.5 & 0.0 & 20.0 & 0.0 \\
\hline 1387 & 8.0 & 6.0 & 5.0 & 7.0 & 1.0 & 1.8 & $\ldots$ & 1.0 & 1.0 & 1.0 & & 1.0 & 0.0 & 0.0 & $\ldots$ & 0.0 \\
\hline 1419 & 4.0 & 3.0 & 3.0 & 7.0 & 1.1 & 1.0 & 1.0 & 1.0 & 1.0 & 1.0 & 1.0 & 1.1 & 0.0 & 0.0 & 0.0 & 0.0 \\
\hline 1541 & 4.0 & 3.0 & 4.0 & 3.0 & 1.3 & 1.0 & 3.5 & 2.7 & 1.0 & 1.0 & 2.3 & 1.0 & 0.0 & 60.0 & 60.0 & 60.0 \\
\hline 1547 & 3.0 & 3.0 & 2.0 & 3.0 & 2.0 & 1.5 & 1.0 & 1.0 & 1.0 & 1.0 & 1.0 & 1.0 & 0.0 & 0.0 & 0.0 & 0.0 \\
\hline 1563 & 3.0 & 4.0 & 2.0 & 3.0 & 2.0 & 1.6 & 3.0 & 1.1 & 1.0 & 1.0 & 1.0 & 1.0 & 0.0 & 0.0 & 0.0 & 0.0 \\
\hline 1575 & 2.0 & 3.0 & 4.0 & 3.0 & 1.2 & 1.0 & 1.0 & 1.1 & 2.0 & 1.0 & 1.0 & 1.0 & 0.0 & 0.0 & 0.0 & 0.0 \\
\hline 1593 & 4.0 & 5.0 & 5.0 & 5.0 & 1.2 & 1.0 & 1.0 & 1.0 & 1.0 & 1.0 & 1.0 & 1.0 & 0.0 & 0.0 & 0.0 & 0.0 \\
\hline 1685 & 3.0 & 9.0 & 8.0 & 8.0 & 1.2 & 1.4 & 1.6 & 1.0 & 1.0 & 1.0 & 1.0 & 1.0 & 0.0 & 0.0 & 0.0 & 0.0 \\
\hline 1704 & 8.0 & 9.0 & 8.0 & 8.0 & 2.5 & 1.7 & 1.9 & 2.5 & 1.1 & 1.0 & 1.0 & 1.4 & 0.0 & 0.0 & 30.0 & 0.0 \\
\hline 1118 & 9.0 & 8.0 & 7.0 & 6.0 & 4.5 & 4.9 & 4.0 & 3.6 & 4.7 & 4.6 & 3.5 & 3.7 & 100.0 & 100.0 & 62.5 & 100.0 \\
\hline Mean & 4.88 & 5.14 & 5.25 & 4.77 & 1.52 & 1.59 & 1.51 & 1.37 & 1.34 & 1.21 & 1.17 & 1.07 & 4.73 & 11.55 & 7.96 & 8.21 \\
\hline LSD I & & & 0.143 & & & & 0.173 & & & & 0.101 & & & & 3.57 & \\
\hline LSD G & & & 0.385 & & & & 0.467 & & & & 0.272 & & & & 9.52 & \\
\hline LSD I-G & & & 0.770 & & & & 0.934 & & & & 0.544 & & & & 19.05 & \\
\hline CV $(\%)$ & & & 0.7 & & & & 4.4 & & & & 2.3 & & & & 4.6 & \\
\hline
\end{tabular}

a Resistant $=\leq 10 \%$ head blast incidence, $\leq 3.0$ score on a 1 -to- 9 scale, and $\leq 2.0$ score on a 1 -to- 5 scale; moderately resistant $=11$ to $30 \%$ head blast incidence, 3.1 to 5.0 score on a 1-to- 9 scale, and 2.1 to 3.0 score on a 1-to-5 scale; susceptible $=31$ to $50 \%$ head blast incidence, 5.1 to 7.0 score on a 1 -to-9 scale, and 3.1 to 4.0 score on a 1 -to- 5 scale; and highly susceptible $=>50 \%$ head blast incidence, $>7.0$ score on a 1 -to- 9 scale, and $>4.0$ score on a 1 -to-5 scale.

${ }^{\mathrm{b}}$ Accession numbers. LSD $=$ least significant difference $(P<0.01)$ for isolate $(\mathrm{I})$, genotype $(\mathrm{G})$, and the isolate-genotype interaction $(\mathrm{I}-\mathrm{G})$; CV $=$ coefficient of variation. 
mation on the virulence structure of foxtail millet-infecting populations of the pathogen in India. Differential reactions to four isolates was observed in 14 accessions (ISe 375, -376, -1059, -1067, -1137, $-1187,-1201,-1204,-1258,-1419,-1541,-1563,-1575$, and -1685 ), indicating possible pathogenic variation in the $M$. grisea populations adapted to foxtail millet in India (Table 3). If confirmed, some of these accessions can be used as host differentials to elucidate pathogenic variation in the foxtail-millet-infecting $M$. grisea isolates collected from the crop-growing areas in India and elsewhere.

Based on the comparative morphology, foxtail millet accessions have been classified into three races: moharia, maxima, and indica (14). In all, 11 of the 24 (46\%) accessions of race maxima included in the foxtail millet core collection exhibited resistance to at least one isolate of M. grisea in the greenhouse screen (Tables 3 and 4). However, none of the 29 accessions from race moharia and only 3 of the 102 accessions of race indica showed blast resistance. Two accessions, ISe 1547 and ISe 1181, of race maxima were found resistant to all four isolates of $M$. grisea, indicating a high level of resistance in race maxima to different populations of $M$. grisea adapted to foxtail millet. Therefore, it will be useful to evaluate the remaining 211 accessions of race maxima available at the ICRISAT gene bank (29) to identify multiple-pathotype resistance in foxtail millet germplasm.

Wide variations for nutrient quality traits (protein, $\mathrm{Ca}, \mathrm{Fe}$, and $\mathrm{Zn}$ content) was observed in the grains of blast-resistant accessions selected from the foxtail millet core collection. ISe 1419, which is resistant to sheath, neck, and head blast against all four isolates and has leaf blast resistance to two isolates (Fx 58 and Fx 60), was among the 26 best accessions with three or more agronomic and nutritional trait $(\mathrm{Ca}, \mathrm{Zn}$, and protein) combinations selected by Upadhyaya et al. (30) from the foxtail millet core collection. Blastresistant accessions ISe 1059, -1181, and -1685, and ISe -1059 and -1187 , were among the trait-specific accessions identified for $\mathrm{Ca}$ and Fe content, respectively (30). ISe 1067 and germplasm check ISe 1541 were identified as the best sources of protein among the 16 blast-resistant accessions. Therefore, these accessions could be used for the development of blast-resistant, nutritionally superior foxtail millet cultivars.

Breeding for improved blast-resistant varieties is an important goal of foxtail millet improvement programs in India. Multiple pathotype-resistant accessions identified in the core collection could be used in breeding programs. Among blast-resistant accessions identified in this study, ISe 376 is an improved cultivar. This accession was found resistant to three of the four isolates tested. In addition, ISe 1685 and ISe 1541 recorded higher grain yields compared with the best control, ISe 1468 (30). Therefore, these agronomically superior blast-resistant accessions can be directly released for cultivation in farmers' fields after thorough testing in yield trials in the relevant locations.

\section{Acknowledgments}

We thank the BMZ/GTZ project on "Sustainable conservation and utilization of genetic resources of two underutilized crops-finger millet and foxtail millet-to enhance productivity, nutrition and income in Africa and Asia" for the financial support to carry out this research.

Table 4. Origin, race, biological status (Status), days to $50 \%$ flowering (Days), plant height, basal tiller number, grain yield (kg ha ${ }^{-1}$ ) (Yield), and protein and minerals contents of the foxtail millet accessions selected from the core collection evaluated during rainy season 2008

\begin{tabular}{|c|c|c|c|c|c|c|c|c|c|c|c|c|}
\hline $\mathbf{I S e}^{\mathbf{a}}$ & Origin & Race & Subrace & Status $^{b}$ & Days & $\begin{array}{c}\text { Height } \\
(\mathrm{cm})\end{array}$ & $\begin{array}{c}\text { Basal } \\
\text { tiller }\end{array}$ & Yield & $\begin{array}{c}\text { Ca } \\
(\mathbf{p p m})\end{array}$ & $\begin{array}{c}\text { Fe } \\
(\mathbf{p p m})\end{array}$ & $\begin{array}{c}\mathbf{Z n} \\
(\mathbf{p p m})\end{array}$ & $\begin{array}{c}\text { Protein } \\
(\%)\end{array}$ \\
\hline 375 & India & Maxima & Assamense & IC & 60 & 85.91 & 1.52 & 666.7 & 126.7 & 40.1 & 42.0 & 11.3 \\
\hline 376 & India & Maxima & Assamense & IC & 57 & 88.19 & 1.54 & 996.4 & 114.6 & 43.9 & 46.4 & 11.4 \\
\hline 748 & India & Indica & Magna & Land & 97 & 132.5 & 2.47 & 693.5 & 154.2 & 43.1 & 60.1 & 16.8 \\
\hline 751 & India & Indica & Glabra & Land & 101 & 103.33 & 2.24 & 561.0 & 221.3 & 49.5 & 55.2 & 16.1 \\
\hline 769 & India & Moharia & Aristata & Land & 89 & 155.45 & 2.27 & 1012.7 & 187.3 & 45.2 & 48.8 & 12.6 \\
\hline 771 & India & Indica & Nana & Land & 59 & 86.91 & 2.83 & 1683.7 & 130.9 & 52.2 & 46.2 & 12.4 \\
\hline 785 & India & Indica & Nana & Land & 54 & 83.6 & 2.49 & 926.2 & 139.6 & 47.0 & 44.4 & 13.0 \\
\hline 846 & India & Indica & Nana & Land & 57 & 92.27 & 2.68 & 1508.3 & 147.3 & 51.1 & 47.9 & 11.9 \\
\hline 1059 & India & Maxima & Spongiosa & Land & 66 & 121.55 & 1.56 & 721.5 & 248.4 & 63.3 & 46.4 & 12.9 \\
\hline 1067 & Syria & Maxima & Compacta & Land & 45 & 43.29 & 1.73 & 322.1 & 143.9 & 49.0 & 43.0 & 15.7 \\
\hline 1137 & Syria & Indica & Nana & Land & 48 & 61.73 & 1.74 & 165.9 & 127.2 & 56.9 & 37.7 & 14.4 \\
\hline 1181 & China & Maxima & Compacta & Land & 43 & 62.2 & 1.39 & 155.8 & 271.6 & 51.8 & 44.6 & 14.9 \\
\hline 1187 & China & Maxima & Compacta & Land & 45 & 44.71 & 1.97 & 109.7 & 107.2 & 58.6 & 45.2 & 13.9 \\
\hline 1201 & China & Maxima & Compacta & Land & 36 & 29.69 & 1.61 & 78.8 & 154.6 & 42.0 & 39.8 & 13.0 \\
\hline 1204 & Russia \& CISs & Maxima & Compacta & Land & 45 & 46.31 & 1.78 & 47.5 & 155.1 & 48.4 & 40.9 & 14.3 \\
\hline 1258 & Russia \& CISs & Maxima & Compacta & Land & 40 & 43.47 & 1.62 & 186.6 & 90.3 & 52.0 & 47.4 & 14.4 \\
\hline 1286 & Turkey & Moharia & Glabra & Land & 36 & 33.07 & 2.55 & 232.5 & 181.5 & 66.0 & 74.2 & 13.5 \\
\hline 1320 & United States & Moharia & Glabra & Land & 30 & 33.78 & 2.37 & 210.7 & 118.5 & 62.2 & 55.9 & 13.7 \\
\hline 1335 & Hungary & Moharia & Glabra & Land & 35 & 37.95 & 1.74 & 77.8 & 154.8 & 55.0 & 50.2 & 16.2 \\
\hline 1387 & Sri Lanka & Indica & Glabra & Land & 83 & 132.75 & 1.74 & 778.6 & 157.3 & 49.3 & 59.3 & 13.2 \\
\hline 1419 & India & Indica & Glabra & Land & 94 & 155.59 & 1.93 & 883.9 & 241.0 & 52.2 & 57.2 & 15.7 \\
\hline 1541 & India & Maxima & Compacta & Land & 75 & 114.79 & 1.97 & 1852.5 & 107.4 & 47.6 & 51.9 & 17.2 \\
\hline 1547 & Korea & Maxima & Compacta & Land & 43 & 51.72 & 1.47 & 150.3 & 113.0 & 37.2 & 33.6 & 11.5 \\
\hline 1563 & Korea & Maxima & Compacta & Land & 39 & 62.88 & 2.28 & 657.3 & 155.9 & 51.1 & 34.3 & 13.9 \\
\hline 1575 & Korea & Maxima & Compacta & Land & 50 & 60.71 & 1.87 & 254.4 & 159.7 & 53.8 & 37.8 & 12.5 \\
\hline 1593 & Korea & Maxima & Compacta & Land & 51 & 60.78 & 1.73 & 420.3 & 144.4 & 43.2 & 37.4 & 13.2 \\
\hline 1685 & India & Indica & Profusa & Land & 80 & 115.73 & 2.11 & 1644.7 & 200.3 & 49.8 & 47.8 & 11.9 \\
\hline 1704 & India & Indica & Nana & Land & 56 & 77.29 & 2.49 & 1531.7 & 148.6 & 58.8 & 55.5 & 12.6 \\
\hline 1118 & Syria & Moharia & Glabra & Land & 42 & 30.02 & 2.63 & 411.5 & 113.6 & 39.7 & 38.4 & 16.0 \\
\hline \multicolumn{13}{|l|}{ Parameters ${ }^{c}$} \\
\hline Range & $\ldots$ & $\ldots$ & $\ldots$ & $\ldots$ & $30-101$ & $29.7-155.6$ & $1.4-3.2$ & $39.9-2349.5$ & $90.3-288.7$ & $24.1-68.0$ & $33.6-74.2$ & $10.7-18.5$ \\
\hline ISe for min & $\ldots$ & $\ldots$ & $\ldots$ & $\ldots$ & 1151 & 1201 & 1181 & 1227 & 1258 & 1129 & 1547 & 931 \\
\hline ISe for max & $\ldots$ & $\ldots$ & $\ldots$ & $\ldots$ & 751 & 1419 & 909 & 1820 & 1227 & 1151 & 1286 & 1312 \\
\hline Trial mean & $\ldots$ & $\ldots$ & $\ldots$ & $\ldots$ & 54.75 & 83.79 & 2.21 & $1,046.32$ & 145.82 & 49.78 & 47.85 & 13.50 \\
\hline LSD & $\ldots$ & $\ldots$ & $\ldots$ & $\ldots$ & 8.23 & 18.87 & 1.05 & 915.82 & 50.79 & 16.57 & 13.65 & 2.26 \\
\hline $\mathrm{CV}(\%)$ & $\ldots$ & $\ldots$ & $\ldots$ & $\ldots$ & 7.75 & 11.66 & 35.54 & 50.54 & 17.76 & 16.89 & 14.42 & 8.55 \\
\hline
\end{tabular}

a Accession numbers.

${ }^{\mathrm{b}} \mathrm{IC}=$ improved cultivar and Land $=$ landrace

${ }^{\mathrm{c}}$ Statistical parameters for 155 accessions of core collection; $\min =$ minimum, $\max =$ maximum, LSD $=$ least significant difference $(P=0.05)$, and $\mathrm{CV}=$ coefficient of variation. 


\section{Literature Cited}

1. Babu, T. K., Thakur, R. P., Upadhyaya, H. D., Narayan Reddy, P., Sharma, R., Girish, A. G., and Sarma, N. D. R. K. 2013. Resistance to blast (Magnaporthe grisea) in a mini-core collection of finger millet germplasm. Eur. J. Plant Pathol. 135:299-311.

2. Bartlett, M. S. 1937. Properties of sufficiency and statistical tests. Proc. R. Stat. Soc. Ser. A 160:268-282.

3. Bhattacharjee, R., Khairwal, I. S., Bramel, P. J., and Reddy, K. N. 2007. Establishment of a pearl millet [Pennisetum glaucum (L.) R. Br.] core collection based on geographical distribution and quantitative traits. Euphytica 155:35-45.

4. Chang, K. C. 1973. Radiocarbon dates from China: some initial interpretations. Curr. Anthropol. 14:525-528.

5. Chen, J. J. 1993. Present status of foxtail millet and proso millet genetic resources conservation in China. Pages 401-406 in: Advances in Small Millets. K. W. Riley, S. C. Gupta, A. Seetharam, and J. N. Mushonga, eds. Oxford \& IBH Publishing Co. Pvt. Ltd., New Delhi, India.

6. Choi, Y., Osada, K., Ito, Y., Nagasawa, T., Choi, M., and Nishizawa, N. 2005. Effects of dietary protein of Korean foxtail millet on plasma adinopectin, HDL-cholesterol and insulin levels in genetically type 2 diabetic mice. Biosci. Biotechnol. Biochem. 69:31-37.

7. D'Souza, T. F., and Gaikwad, A. P. 1984. Varietal resistance of setaria (Setaria italica) to blast caused by Pyricularia setariae. Indian Phytopathol. 37:605-607.

8. Frankel, O. H., and Brown, A. H. D. 1984. Plant genetic resources today: a critical appraisal. Pages 249-268 in: Crop Genetic Resources: Conservation and Evaluation. J. H. W. Holden and J. T. Williams, eds. Allen and Unwin, Winchester, MA.

9. Gaikwad, A. P., and D'Souza, T. F. 1986. Studies on blast disease of Rala Setaria italica. J. Maharashtra Agric. Univ. 11:108-109.

10. IBPGR. 1985. Descriptors of Setaria italica and S. pumila. IBPGR, Rome.

11. Li, Y., Wu, S., and Cao, Y. 1995. Cluster analysis of an international collection of foxtail millet (Setaria italica (L.) P. Beauv.). Euphytica 83:79-85.

12. Nakayama, H., Nagamine, T., and Hayashi, N. 2005. Genetic variation of blast resistance in foxtail millet (Setaria italica (L.) P. Beauv.) and its geographic distribution. Genet. Resour. Crop Evol. 52:863-868.

13. Prabhu, A. S., Filippi, M. C., and Castro, N. 1992. Pathogenic variation among isolates of Pyricularia grisea infecting rice, wheat, and grasses in Brazil. Trop. Pest Manage. 38:367-371.

14. Prasada Rao, K. E., de Wet, J. M. J., Brink, D. E., and Mengesha, M. H. 1987. Intraspecific variation and systematics of cultivated Setaria italica, foxtail millet (Poaceae). Econ. Bot. 41:108-116.

15. Prasada Rao, K. E., de Wet, J. M. J., Reddy, V. G., and Mengesha, M. H. 1993. Diversity in small millet collection at ICRISAT. Pages 331-346 in: Advances in Small Millets. K. W. Riley, S. C. Gupta, A. Seetharam, and J. N. Mushonga, eds. Oxford \& IBH Publishing Co. Pvt. Ltd., New Delhi, India.

16. Rai, M. 2002. Nutritive cereals. Pages 59-62 in: Survey of Indian Agriculture. The Hindu, Chennai, Tamil Nadu, India.

17. Sahrawat, K. L., Ravi Kumar, G., and Rao, J. K. 2002. Evaluation of triacid and dry ashing procedures for determining potassium, calcium, magnesium, iron, zinc, manganese and copper in plant materials. Commun. Soil Sci. Plant Anal. 33:95-102.

18. Seetharam, A., Aradhya, K. M., and Laxminarayana, M. R. 1983. Variation for seed oil content in a world collection of foxtail millet germplasm. Sabrao J. 15:99.

19. Seetharam, A., Riley, K. W., and Harinarayana, G. 1989. Small Millets in Global Agriculture. Oxford \& IBH Publishing Co., New Delhi, India.

20. Sema, A., and Sarita, S. 2002. Suitability of millet-based food products for diabetics. J. Food Sci. Technol. 39:423-426.

21. Sharma, R., Upadhyaya, H. D., Manjunatha, S. V., Rai, K. N., Gupta, S., and Thakur, R. P. 2013. Pathogenic variation in the pearl millet blast pathogen, Magnaporthe grisea and identification of resistance to diverse pathotypes. Plant Dis. 97:189-195.

22. Singh, U., and Jambunathan, R. 1980. Evaluation of rapid methods for the estimation of protein in chickpea (Cicer arietinum L.). J. Sci. Food Agric. 31:247-254.

23. Sirithunya, P., Tragoonrung, S., Vanavichit, A., Vongsaprom, C., and Toojinda, T. 2002. Quantitative trait loci associated with leaf and neck blast resistance in recombinant inbred line population of rice (Oryza sativa). DNA Res. 9:79-88.

24. Sreenivasulu, M. R., Mohan Rao, V., and Sreeramulu, C. 1984. Varietal reaction of setaria (Setaria italica Beauv.) to blast Pyricularia grisea (Cooke Saccard) disease. Madras Agric. J. 71:136-137.

25. Suh, J. P., Roh, J. H., Cho, Y. C., Han, S. S., Kim, Y. G., and Jena, K. K. 2009. The Pi40 gene for durable resistance to rice blast and molecular analysis of Pi40-advanced backcross breeding lines. Phytopathology 99:243-250.

26. Takan, J. P., Chipili, J., Muthumeenakshi, S., Talbot, N. J., Manyasa, E. O., Bandyopadhyay, R., Sere, Y., Nutsugah, S. K., Talhinhas, P., Hossain, M., Brown, A. E., and Sreenivasaprasad, S. 2012. Magnaporthe oryzae populations adapted to finger millet and rice exhibit distinctive patterns of genetic diversity, sexuality and host interaction. Mol. Biotechnol. 50:145-158.

27. Upadhyaya, H. D., Gowda, C. L. L., Reddy, K. N., and Singh, S. 2009 Augmenting the pearl millet core collection for enhancing germplasm utilization in crop improvement. Crop Sci. 49:573-580.

28. Upadhyaya, H. D., Ortiz, R., Bramel, P. J., and Singh, S. 2003. Development of a groundnut core collection using taxonomical, geographical and morphological descriptors. Genet. Resour. Crop Evol. 50:139-148.

29. Upadhyaya, H. D., Pundir, R. P. S., Gowda, C. L. L., Reddy, V. G., and Singh, S. 2008. Establishing a core collection of foxtail millet to enhance the utilization of germplasm of an underutilized crop. Plant Genet. Resour. 7:177-184

30. Upadhyaya, H. D., Ravishankar, C. R., Narasimhudu, Y., Sarma, N. D. R. K., Singh, S. K., Varshney, S. K., Reddy, V. G., Singh, S., Parzies, H. K. Dwivedi, S. L., Nadaf, H. L., Sahrawat, K. L., and Gowda, C. L. L. 2011. Identification of trait-specific germplasm and developing a mini core collection for efficient use of foxtail millet genetic resources in crop improvement. Field Crops Res. 124:459-467.

31. Wald, A. 1943. Test of statistical hypotheses concerning several parameters when the number of observation is large. Trans. Am. Math. Soc. 54:426 482.

32. Yan, W. G., Rutger, J. N., Bryant, R. J., Bockelman, H. E., Fjellstrom, R. G., Chen, M. H., Tai, T. H., and McClung, A. M. 2007. Development and evaluation of a core collection of the USDA rice germplasm collection. Crop Sci. 47:869-876

33. Yan, W. Y., Xie, S. Y., Jin, L. X., Liu, H. J., and Hu, J. C. 1985. A preliminary study on the physiological races of millet blast (Pyricularia setariae Nishik.). Sci. Agric. Sin. 3:57-62. (In Chinese with English summary) 